puesto para el Premio Nobel de la Paz por su trabajo en el acuerdo); en el encuentro que mantiene con Fidel Castro para evitar la internacionalización del conflicto, llegando a ser incluido en una lista de los que debían ser asesinados; o en su participación activa en el canje de prisioneros políticos, al arriesgar su vida en cada encuentro en países como Colombia, Nicaragua, Perú, Chile o Ecuador, por mencionar algunos de los ejemplos que se detallan a lo largo de la obra.

Con el calificativo de "constructor de puentes" es conocido en distintos horizontes de la Iglesia latinoamericana, pues su labor hacia el diálogo desde la prudencia y su participación activa en las transformaciones sociales y políticas cuentan la vida de este obispo; en este caso, desde la mirada de un profesor chileno afincado en Ecuador, que intenta acercase a la experiencia del sacerdote alemán para rescatar su misión y compartirla en tanto orienta su mensaje al cuidado de la dignidad de la persona, consagrada en su esperanza hacia la compasión del prójimo.

Queda a la reflexión del lector el aporte de este "Obispo Constructor" a la cultura política, social y religiosa del Ecuador y de Latinoamérica.

Fernando Lara Lara

Pontificia Universidad Católica del Ecuador, Sede Santo Domingo

\title{
Édison Macías Núñez. General Guillermo Rodríguez Lara. Quito: Editogran / Medios Públicos EP, 2017, 300 pp.
}

\section{DOI: http:/ / dx.doi.org/10.29078/rp.v0i48.704}

En la operación historiográfica se utilizan los testimonios orales como una herramienta para la reconstrucción del pasado. La hegemonía del presente sobre el pasado en el discurso histórico es del orden de la experiencia y está sostenido, en el caso del testimonio, por la memoria y la subjetividad. ${ }^{1}$

Es importante conocer los diversos datos que se han producido en la memoria de las personas, percibir algo que no sabemos o no tenemos modo de conocer. ${ }^{2}$ El libro intitulado General Guillermo Rodríguez Lara, escrito por el teniente coronel en servicio pasivo Édison Macías Núñez, presenta una reconstrucción histórica estableciendo una conexión entre testimonio y memo-

1. Paul Ricoeur, La memoria, la historia, el olvido (Buenos Aires: Fondo de Cultura Económica, 2013), 65.

2. Alessandro Portelli, "Lo que hace diferente a la historia oral". En La historia oral, comp. por Dora Schwarzstein (Buenos Aires: Centro Editor de América Latina), 37. 
ria, partiendo del relato oral de experiencias y narración de acontecimientos sobre la vida del general mediante entrevista, cotejando los hechos históricos de su vida con fuentes escritas y estudiando sus archivos personales con fotografías familiares.

El libro tiene doce capítulos. En ellos, el autor analiza los primeros años del general en su natal Pujilí, sus progenitores y hermanos. Su educación primaria, secundaria y la legitimidad de identificar tempranamente su vocación: "la carrera de las armas".

Macías determina las cualidades académicas del cadete Guillermo Rodríguez durante su formación en el Colegio Militar, quien luego de destacarse entre sus compañeros, obtuvo una beca que le permitió graduarse con honores como subteniente del arma de ingeniería en la Escuela Militar José María Córdova de Colombia. Continuaría sus estudios en la Escuela de Artillería e Ingenieros, y al obtener las más altas calificaciones fue enviado a continuar con su preparación en la Escuela Superior Técnica de Argentina, donde se graduó exitosamente de ingeniero civil, conocimientos que, según el autor, los aplicó como oficial superior del Ejército ecuatoriano y cuando dirigió los destinos del país presidiendo el Gobierno Militar (1972-1976).

El texto revela también la unión matrimonial con su compañera de toda una vida, Aída Judith León Lara, y sus hijos. En este sentido, el autor discute y considera la carrera militar como una profesión de relaciones humanas, con características propias que la distinguen del resto de las profesiones en el marco de la sociedad.

El texto retoma y presenta al oficial ecuatoriano como profesor de la Escuela de las Américas, quien, a solicitud del Ejército y del Gobierno de los Estados Unidos, instruyó a oficiales alumnos de diferentes países. Se resalta, también, al alumno e instructor de la Academia de Guerra del Ejército ecuatoriano, al director del Colegio Militar y al general de la República, que mostró sus reconocidas capacidades de docente durante una trayectoria militar en la que formó a gran cantidad de estudiantes civiles y militares.

Édison Macías analiza los acontecimientos que provocaron el derrocamiento de José María Velasco Ibarra durante el Carnaval del 16 de febrero de 1972 y da a conocer cómo fue que llegaron al poder las Fuerzas Armadas, con el gobierno revolucionario y nacionalista encabezado por Rodríguez Lara.

Se resalta, en este libro, la promulgación de la Ley de Aguas, de Fomento Pesquero y Minero, la aplicación de la Ley de Hidrocarburos, la creación como entidad pública de la Corporación Estatal Petrolera Ecuatoriana (CEPE), el impulso de Transnave, la Ley de la Reforma Agraria, la creación de la Dirección de Industrias del Ejército (DINE), la construcción de la Refinería de Esmeraldas, la incorporación del Ecuador a la Organización de Países Exportadores de Petróleo (OPEP), la creación del Instituto Oceano- 
gráfico Ecuatoriano y la adquisición de armamento y equipo para Fuerzas Armadas. Estos logros son descritos por Macías como aspectos positivos de un proceso de transformación y crecimiento del país. Así como también la actitud de rechazo a injerencias o presiones de gobiernos extranjeros, como la no participación en la denominada "Operación Cóndor" en la que participaron varios regímenes militares del Cono Sur.

Además, Edison Macías Núñez reflexiona en este libro sobre los aspectos negativos del régimen presidido por Rodríguez Lara, que fueron censurados por la prensa nacional y por sus adversarios políticos, como el crecimiento burocrático, la creación de tribunales de justicia especiales, el incremento de precios de artículos de primera necesidad que el gobierno no pudo controlar adecuadamente, el fracaso de la reforma agraria que propició crisis en el campo, la represión violenta de huelgas y protestas estudiantiles, entre otras. Finalmente, se mencionan también los arrestos a varios dirigentes políticos, muchos de los cuales fueron confinados a destacamentos militares en el Oriente ecuatoriano. Estos hechos provocaron descontento paulatino en varios sectores de la sociedad ecuatoriana.

El libro reseñado presenta una recreación narrativa conjunta entre el testigo y el historiador, basados en los recuerdos y vivencias de Rodríguez Lara. Alessandro Portelli define a esta técnica como "premio y maldición de la Historia Oral: la subjetividad", proceso mediante el cual los individuos expresan los sentidos de sí mismos en la historia. Para evitar este tipo de representaciones, el autor-editor de la obra cotejó la información proporcionada por el testimoniante con fuentes escritas.

Como oficial del Ejército ecuatoriano, historiador e integrante del Centro de Estudios Históricos del Ejército (CEHE), considero que esta biografía representa un importante aporte a la historia militar de la institución castrense, fortaleciendo de esta manera la identidad militar y la imagen cultural de la Fuerza Terrestre del Ecuador.

Con este volumen, se inicia la publicación de un conjunto de libros de carácter histórico y de interés profesional, con biografías de líderes militares con incidencia histórica en el acontecer institucional, nacional y mundial. Un proyecto que se propone recuperar y divulgar el patrimonio histórico del Ejército ecuatoriano.

Jorge Martínez Bucheli

Centro de Estudios Históricos del Ejército / Universidad Andina Simón Bolivar, Sede Ecuador 